\title{
ORGANISING FOR COMMON SYSTEMS
}

by

N.I. Richards

Systems Development Manager,

Gold and Uranium Division,

Anglo American Corporation of South Africa Limited

\section{SYNOPSIS}

It is argued that to design large, common information systems and implement them in several locations needs a special organisation. Most sites where such systems are to be installed have different organisation structures which makes the development process difficult. Internally, most Information Systems Departments do not have the control procedures in place which will give adequate forewarning that projects of this type are not producing an acceptable systems solution. This paper describes the way that the Gold Division of Anglo American have tackled these and associated problems. 


\section{INTRODUCTION}

In this paper I will describe the methodology that we use to develop large Information Systems, together with some problems that have been experienced by ourselves and some other major South African Companies. The companies who have been cited, albeit anonymously, are, likewise large, capital intensive firms which are geographically distributed into semi autonomous sites.

Large being a relative description of size, requires me to give a few statistics about The Anglo American Corporation of South Africa.

Anglo American Corporation is the head of an international group of mining, industrial and investment companies which it administers in South Africa and elsewhere. We have close associations with De Beers Consolidated Mines Iimited, Charter Consolidated Limited (in London), Engelhard Minerals and Chemicals Corporation (in USA) and Hudson Bay Mining and Smelting Company (Canada).

The Group's main interests are, however, in Southern Africa where income is derived from gold (44\%), diamonds (17\%), copper (9\%), industrial companies (16\%), coal (3\%), other mining activities $(2 \%)$, finance $(6 \%)$ and platinum (3\%).

Anglo's Gold and Uranium Division is responsible for the management of our ten major gold mining companies operating in South Africa. Production from these mines amounts to about $40 \%$ of South Africa gold production and $30 \%$ of world production.

This is an impressive operation. The gold mines which are spread over a wide geographical area employ one hundred and fifty thousand people, have a capital expenditure each year of $\$ 200$ milition and working costs of $\$ 630$ million.

Yet the evolution of the Division's use of computers has been very slow. 
Table 1 shows, however, that since 1976 a build-up is certainly now under way:

\begin{tabular}{|c|c|c|c|c|}
\hline Year & $\begin{array}{l}\text { Hardware } \\
\text { Installed }\end{array}$ & $\begin{array}{l}\text { Operating } \\
\text { System }\end{array}$ & $\begin{array}{l}\text { Principal systems } \\
\text { in Development }\end{array}$ & $\begin{array}{c}\text { Principal systems } \\
\text { in Operation }\end{array}$ \\
\hline 1970 & $1 \times$ IBM $360 / 40$ & DOS & - & $\begin{array}{l}\text { - Stores } \\
\text { 'Payroll }\end{array}$ \\
\hline 1972 & $2 \mathrm{x}$ IBM $360 / 40$ & DOS & - & $\begin{array}{l}\text { - Stores } \\
\text { "Payroll }\end{array}$ \\
\hline 1974 & $2 \times$ IBM $370 / 135$ & DOS & - & $\begin{array}{l}\text { - Stores } \\
\cdot \text { Payroll }\end{array}$ \\
\hline 1976 & $\begin{array}{llll}1 & x & \text { IBM } & 370 / 158 \\
1 & x & \text { IBM } & 370 / 135\end{array}$ & os/vs & $\begin{array}{l}\text { Personnel } \\
\text { Management }\end{array}$ & $\begin{array}{l}\text { 'stores } \\
\text { 'Payroll }\end{array}$ \\
\hline 1977 & IBM $370 / 158 \mathrm{MP}$ & OS/MVS & $\begin{array}{l}\text { - Personnel } \\
\text { Management } \\
\text { ·Mine Planning } \\
\text { 'Geological } \\
\text { Information } \\
\text { 'Materials } \\
\text { Control }\end{array}$ & $\begin{array}{l}\text { "Stores } \\
\text { "payroll }\end{array}$ \\
\hline
\end{tabular}

TABLE 1 : EVOLUTION OF DATA PROCESSING IN GOLD DIVISION

The main reason for this acceleration is that in $1975 / 76$ the Division became dissatisfied with the way the computer was being used as a Management Information tool. It therefore undertook a BSP study (Business Systems Planning) whose purpose was to:

- create the basic systems theory that would be used in the Division

- review the Management's requirements for Information

- define the Division's business processes

- develop a strategy for providing required information 


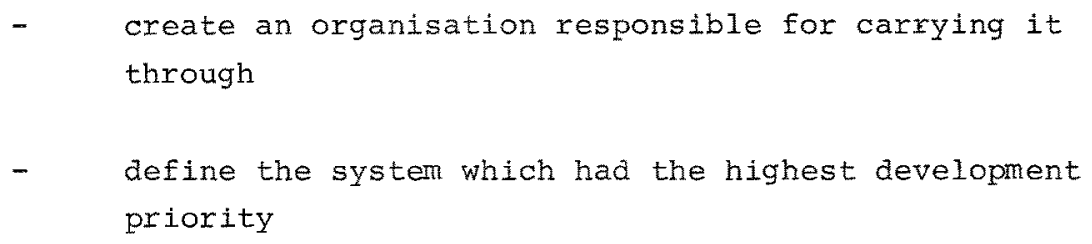

The study took more than seven man years to complete. It involved a large number of interviews with people from all levels of management who were asked a series of searching questions about their Information needs and the benefits that would accrue if they got them. I do not intend to dwell on the BSP methodology. Your friendly IBM salesman would be only too willing to describe it. I would say, though, that as a method for developing a long term Information systems plan, it is very useful. It certainly gave us a highly committed Top Management and a wide visibility on the mines but, for reasons that are internal to an Information Systems Department, I believe BSP should only be used by a company who is able to ensure a tight quality control over the manner in which the study is carried out. A company which has effective project control standards in operation would be ideal. unfortunately, we did not have this absolutely essential discipline, and consequently, as I shall describe, we created many problems for ourselves.

\section{SYSTEMS THEORY}

I will describe the basic systems theory that we have adopted because I believe, and my company believes, that without a similar credo, an information systems man will never implement a successful system. Even though we systems people are trying to be a practical profession, we must nevertheless always remember that a systems theory is necessary. "The theory inspires and informs the practice, and the practice confirms and modifies the theory." 1

The theory that we are using evolved from reading many authorities. One book in particular which I found very instructive, especially in the way that it concerned effective relationships with Users, was by Oliver Wight. ${ }^{2}$ I have borrowed themes from this book quite often in this paper for which I acknowledge my debt.

Our theory can be reduced to 8 basic rules, which are shown in Table 2 : 


\begin{tabular}{|c|c|c|}
\hline Rule & 1: & $\begin{array}{l}\text { The User is responsible for realising the business } \\
\text { improvements that Information Systems can produce. }\end{array}$ \\
\hline Rule & $2:$ & The User owns the system. \\
\hline Rule & $3:$ & $\begin{array}{l}\text { Information systems must only be considered as a } \\
\text { means to an end - they are not an end in themselves }\end{array}$ \\
\hline Rule & $4:$ & $\begin{array}{l}\text { The User must be heavily involved in Information } \\
\text { Systems development. }\end{array}$ \\
\hline Rule & 5: & $\begin{array}{l}\text { The User must be continually reviewing the develop- } \\
\text { ment of the system to ensure that he can accept } \\
\text { responsibility for systems success. }\end{array}$ \\
\hline Rule & $6:$ & $\begin{array}{l}\text { The User must understand the system and come to } \\
\text { depend on it. }\end{array}$ \\
\hline Rule & $7:$ & Unnecessary embellishments are not allowed. \\
\hline Rule & 8: & $\begin{array}{l}\text { The only way to determine the success of a system } \\
\text { is to show that the operation improved after using } \\
\text { it. Therefore evaluation criteria are essential. }\end{array}$ \\
\hline
\end{tabular}

TABLE 2: THE 8 RULES TO ENSURE SYSTEMS SUCCESS.

It can be seen that we intend to keep our Users in the vanguard of the systems development effort and the systems people where they should be - as catalysts and technical supporters. We believe that, unlike process control systems which are able to regulate such processes as oil refining and electricity distribution, the systems that Gold Division produces, Information Systems, will never control our business. We believe that only people will do that. Information systems are purely a "tool of the trade" of a manager. Therefore it is logical to presume that only the user will ever get the improvements from an Information system. He should, as part of his management responsibility, be always designing improvements to the way he runs his function. The computer can often help him to attain these improvements by giving him better information faster, but the fact remains that the responsibility for determining what he wants, for developing these improvements, and for obtaining the desired results belongs to the Users - not the systems people. We systems 
people, for our part, must never see ourselves as the specifiers of the Users systems requirements. It is quite possible that, when developing a system, we will initiate an idea and try to have it included in the design, but, if the user manager, who really has the responsibility, does not consider it acceptable whether or not this is due to his lack of perception or our lack of business appreciation, we must accept his decision. Similarly, we must never add that "bel1" or "whistle" which, though not essential, would complete the symmetry of our design. This is certain to put the whole system at risk by placing it on to the next level of complexity. Our approach has, on the face of it, little to attract a systems man. Gone is the Sir Galahad image he has enjoyed up till now. Indeed, when a system is seen to be a success the User is quite likely to think that it was all his own work. Therefore, if this approach to Systems Development is to be used, a large responsibility is placed on Information Systems management to recognise the good systems man. This recognition is something that must be actively sought out, because the more successful the systems man is, the more the success is apparently due to somebody else.

\section{INEORMATION SYSTEMS ORGANISATION}

The next logical step in describing our methodology is to consider four things:

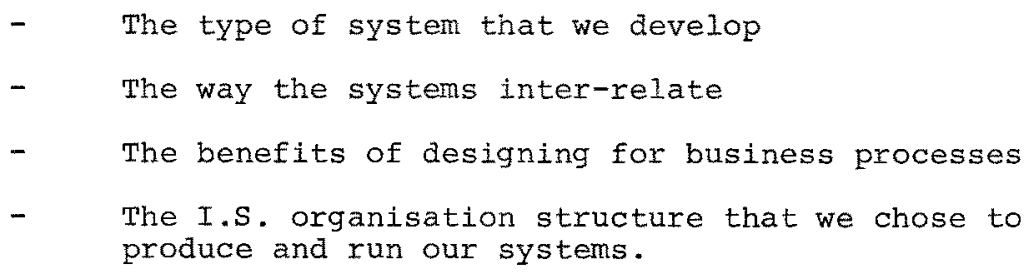

\subsection{SYSTEM TYPES}

We categorise our Information Systems into four categories (as shown in Table 3).

Central systems - developed by a single project team for a User who is centrally based (e.g. at Head Office), who is solely responsible for the co-ordination of the multiple users and for submitting the input, and who therefore acts as a central authority. The system is identical at all sites. In our case, our stores and Payroll systems are run on this basis. 
- Common Systems - developed by a single project team for Users based on every mine, where there is no central submission of input but where a Head office manager has functional control over the system. The system is identical for all mines.

- Shared systems - developed by a single project team for a User based at one mine. When the system is proved to be a success at this mine, it is offered to the others on a "no guarantee and no maintenance" basis. There is no central submission of input, nor has Head office functional control. A mine which accepts such a system is responsible for its own maintenance and therefore, gradually, the system becomes unique to a particular mine.

- Local Systems - developed by a single project team, for a User based at one mine. The system is of a local nature which no other mine wishes to use. Shared systems start out like this.

\begin{tabular}{|l|c|c|c|c|}
\hline $\begin{array}{c}\text { Type of } \\
\text { System }\end{array}$ & $\begin{array}{c}\text { No. of Develop- } \\
\text { ment Sites }\end{array}$ & $\begin{array}{c}\text { No. of Instal- } \\
\text { lation Sites }\end{array}$ & $\begin{array}{c}\text { No. of Main- } \\
\text { tenance Sites }\end{array}$ & End User \\
\hline 1. Central & Single & Single & Single & Multiple \\
\hline 2. Common & Single & Multiple & Single & Multiple \\
\hline 3. Shared & Single & $\begin{array}{c}\text { Single } \\
\text { Multiple) }\end{array}$ & $\begin{array}{c}\text { Single } \\
\text { Mulitiple) }\end{array}$ & $\begin{array}{c}\text { Single } \\
\text { (leading } \\
\text { to } \\
\text { Multiple) }\end{array}$ \\
\hline Local & Single & Single & Single & Single \\
\hline
\end{tabular}

TABLE 3: TYPES OF SYSTEM DEVELOPMENT IN MULTI-LOCATION COMPANIES

The systems which we have identified as being part of our long term strategy belong, to the Central Common and Shared categories and are always developed using a standardised approach. Our choice of preferring the systems which allowed a standardised approach was deliberate, notwithstanding the disadvantages of this 
method. We felt that the advantages (see Table 4) outweighed the disadvantages (see Table 5) and that, by organisational means, we could overcome the major arawbacks.

\begin{tabular}{|c|c|}
\hline 1. & $\begin{array}{l}\text { Easier to develop - less time to design - more use of } \\
\text { commercial packages. }\end{array}$ \\
\hline 2 . & $\begin{array}{l}\text { Easier to train - system can be seen in operation at other } \\
\text { sites, training programme becomes increasingly refined. }\end{array}$ \\
\hline 3. & Better communication between sites - all on same system. \\
\hline 4. & Is the accepted standard tool - no more unique approaches \\
\hline 5. & No more arguments about which way is best. \\
\hline 6. & $\begin{array}{l}\text { Maximises use of scarce development resources (especially } \\
\text { D.P. Personnel) }\end{array}$ \\
\hline
\end{tabular}

TABLE 4: BENEFITS OF STANDARD APPROACH TO SYSTEMS DEVELOPMENT

\begin{tabular}{|c|l|}
\hline 1. & Computer gets blamed for the standards that are needed anyway \\
\hline 2. & Systems have a Head-Office-imposed image. \\
\hline 3. & Individual needs are sacrificed. \\
\hline 4. & Systems tend to be compromises. \\
\hline 5. & Designers have no intimate familiarity with local problems. \\
\hline 6. & Slow response to users need for operational system. \\
\hline 7. & $\begin{array}{l}\text { No identification with the objectives of local management } \\
\text { divisional need catered for only . }\end{array}$ \\
\hline 8. & Difficult to use because of an in-built rigidity. \\
\hline 9. & Common systems are often impractical in local circumstances \\
\hline 10. & Operating level not in sympathy, so difficult to implement. \\
\hline
\end{tabular}

TABLE 5: DISADVANTAGES OF STANDARD APPROACH TO SYSTEMS DEVELOPMENT . 


\subsection{HOW OUR SYSTEMS INTER-RELATE}

As part of the BSP study, we produced:

- a list of required systems in priority order and

- a conceptual network diagram of how they interconnected.

Figure 1 is a sample extract from the total I.S. Network showing the systems with which we have initially been concerned.

As can be seen, we believe that systems only interface by transferring data. Therefore, if one controls the data, one controls the interface.

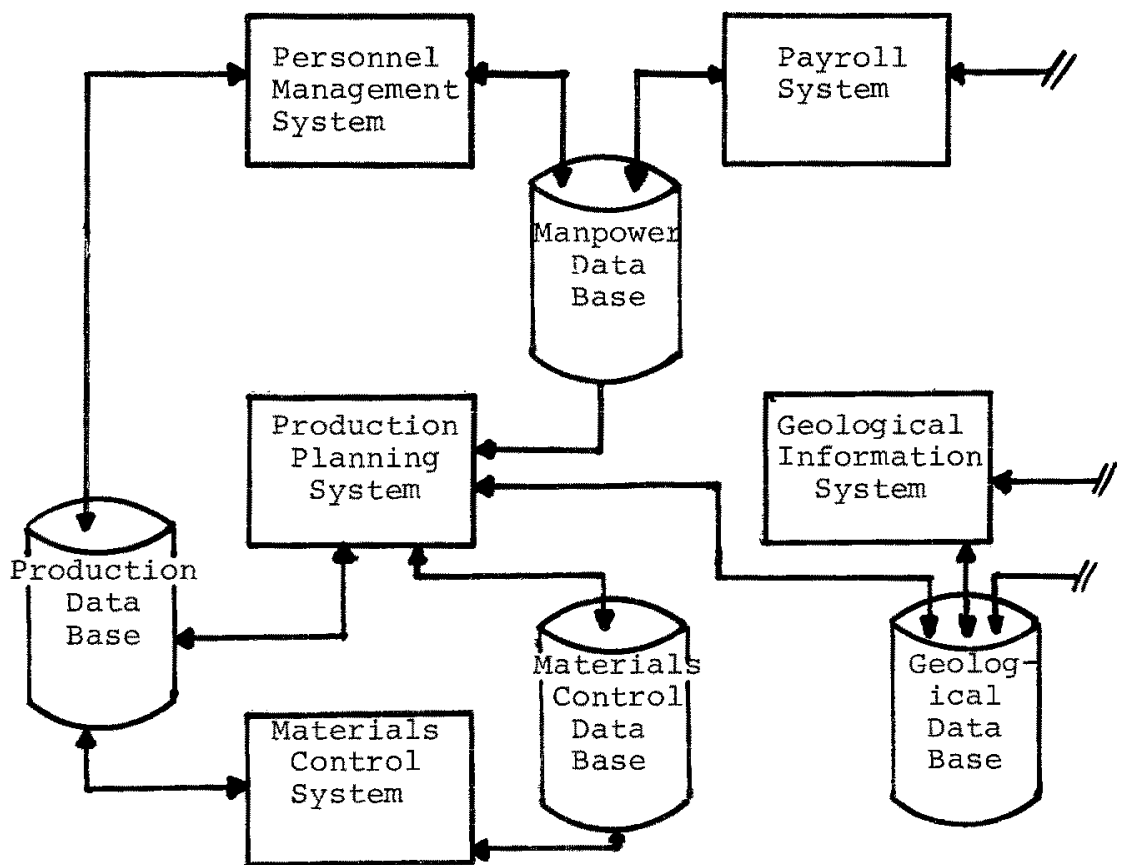

FIGURE 1: EXTRACT FROM INFORMATION SYSTEMS NETWORK

\subsection{DESIGNING FOR BUSINESS PROCESSES}

A few companies are fortunate in that their remote locations have similar organisation structures. This gives standard job titles and standard job descriptions. It does not occur very often though. In most companies, as is the case with our own mines, the locations are semi-autonomous. They each have a different history, make 
different products, or have different management styles, and, consequently, have evolved different organisation structures. Even where job titles might be similar, the job content is almost certain to be different. This, on the face of it, makes the design of common systems impossible - there being no common denominator. However, there is a technique which copes with this situation. We discovered it in the BSP study. In fact, to my mind, it was the best technique to come out of BSP. It was to design systems around business processes.

A company has many business processes. In Gold Mining, we have the Exploration Process, where geologists search for prospective sites for boreholes. When a mine is to be established there is the New Investment process which arranges shaft sinking, etc. After the mine is in operation, there are a series of processes such as Exploitation, Recovery, Administration, Materials, etc. Each process can be broken down to sub-processes. Materials sub-divides into Inventory Management, Maintenance, Requisition, Issue, etc. When we get to the lower levels, it matters little what the organisation structure of the various sites at which the process is performed looks like, or what the job title is of the person who performs each of the various activities. The process is, or could be made to be, the same. This then is the basis on which we design our systems. of course it means that implementation is different for each mine, but as I shall describe, we feel that this is another example where we can solve the problem by organisational means.

\subsection{INFORMATION SYSTEMS ORGANISATION}

The objective of our Information Systems Department is to produce and run information systems. As already stated, we have identified and given a priority to all currently required systems. These have been documented in the form of a conceptual network, an extract of which was shown in Figure 1. In order to carry out our objectives, we have a functional organisation as shown in Figure 2.

This shows that the line functions produce and run the systems and the two staff functions exercise control over the line. This type of organisation is standard and well known except, possibly, for Box 2 - Systems Integration - which I will describe in more detail. 


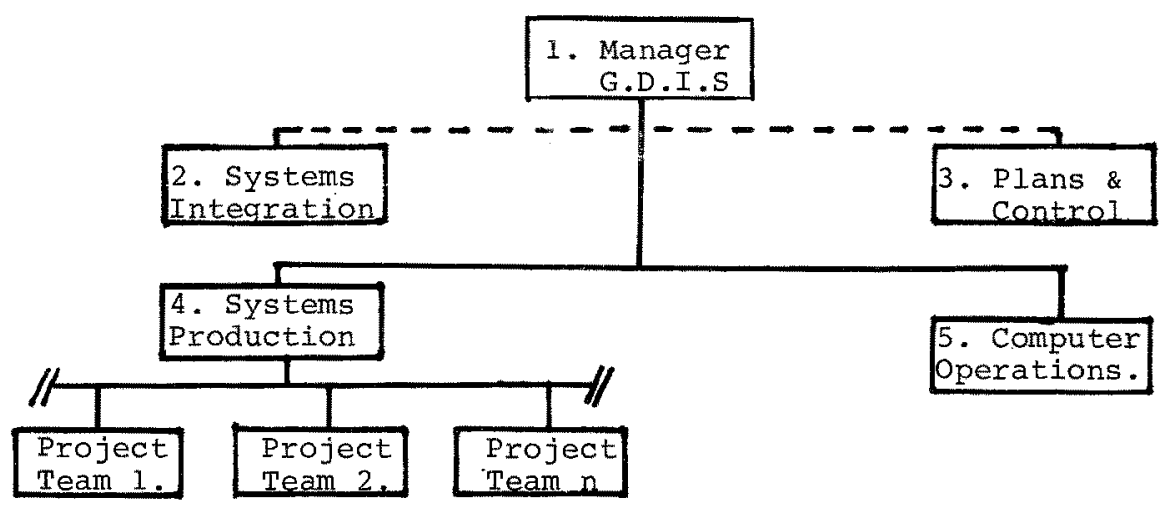

\section{FIGURE 2: GOLD DIVISION INFORMATION SYSTEMS FUNCTIONAL ORGANISATION.}

The purpose of Systems Integration is to provide staff control by safeguarding the integrity of the:

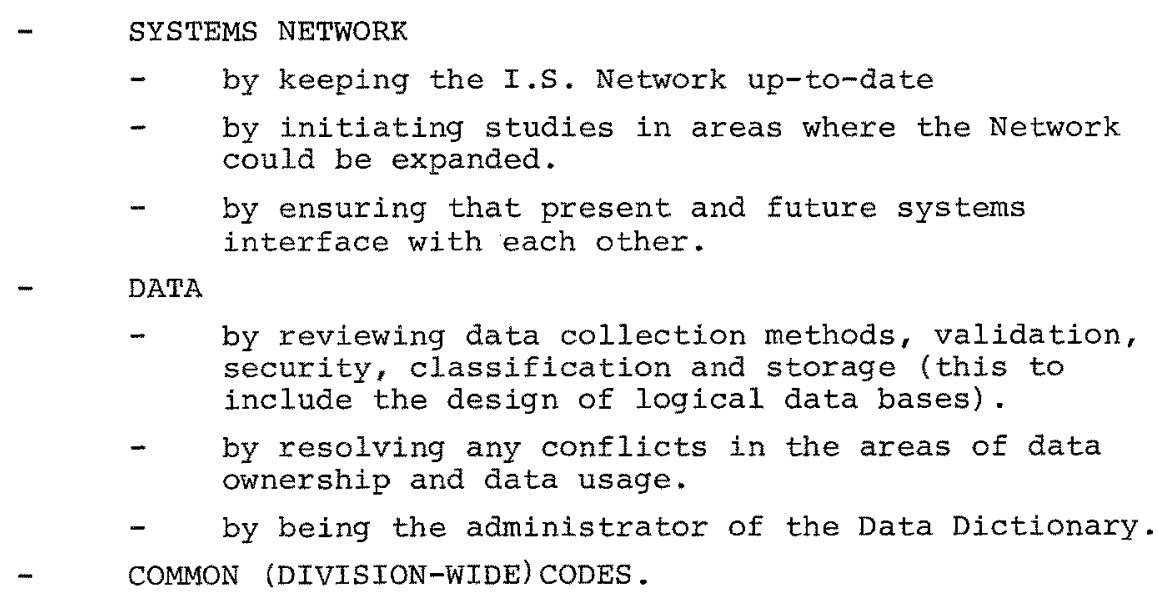

We consider this to be a function of major importance and yet there are not many appointments to this type of position. Many companies to whom we spoke in Europe and America expressed the wish that they could have established a systems Integration function when they were embarking on a network of systems as we are currently doing.

\section{PROJECT MANAGEMENT}

Consider a few statistics:

- The divison employs 130,000 black mine workers whose average tour of duty lasts eight months, giving an 
annual turnover of over 200,000 people.

- There are over 1,000 white supervisors responsible for developing their sets of production plans each month. A set consists of one production plan together with six supporting resource requirement plans.

- There are over 7,000 survey measurements which have to be taken monthly and then plotted on maps and translated into production and other statistical figures.

- There have been 2,500 surface boreholes and over 50,000 underground boreholes drilled in the Witwatersrand Basin, where our mines are situated. None of this data is currently available in computer files.

This serves to show that the systems we are undertaking are major systers which will take several years to develop and implement. We therefore have a series of directives which the manager of a project must follow.

\subsection{DIRECTIVES TO PROJECT MANAGERS}

- All projects must conform with the standard phases shown in Figure 3.

- All projects which will take more than one year to develop must be broken down into "deliverables" - firstly in order to produce a faster return on the investment in development and secondly to keep the project in the User's eye.

- A deliverable - which is the General Design, the production and the testing of a subset of the complete project - must take no longer than six months to complete.

- Formal documentation must be produced before a phase can be considered complete.

- Review approvals must be formally obtained before the project can proceed to the next phase.

This being a practical paper, I must admit to a problem with the six month yardstick for the "deliverables". This has been difficult to achieve in practice. Maybe this is because we are relatively inexperienced in breaking down a project into "deliverables" or 


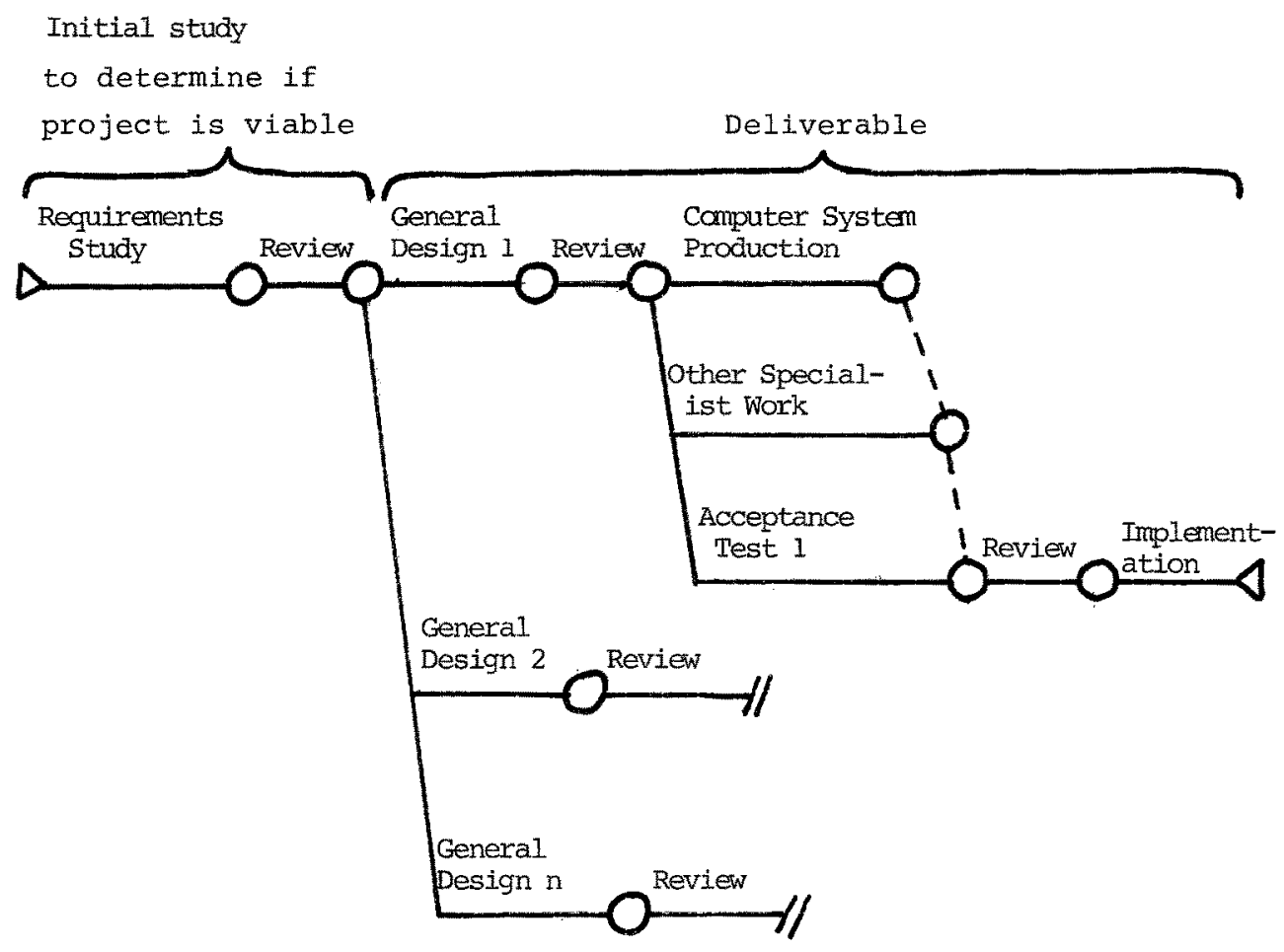

FIGURE 3: STANDARD PHASES USED IN INFORMATION SYSTEM PROJECTS

because we have encountered true exceptions where deliverables cannot be used. In our Personnel Management System, our first deliverable included not only the collection of basic data about each of our mining workers but also included the creation of the infrastructure on which the system would operate. This included the acquisition and installation of a IBM $370 / 158 \mathrm{MP}$, the upgrading of the operating system to MVS, the installation of a pilot terminal network on one of our mines, the creation of several new organisations (e.g. Network Control, Data Base support, on Line systems support), and the formation of various User review bodies. In our Materials control system, our first deliverable was to rewrite our existing stores system. This was found to be completely undocumented - save for program listings - and had been designed so that we could not isolate a meaningful portion of the system to rewrite. It was all or nothing. Except for these two experiences, however, it seems that the other projects, and even later deliverables in these projects will be able to use the deliverables concept to good effect. 


\subsection{PROJECT MANAGER}

Before an Information System can be produced and implemented, two important questions must be answered:

- What does the Project need to do?

- How are we goinc to do it?

The people able to answer these questions have completely different backgrounds. From our System theory, we hold the User responsible for the specification of requirements. Therefore in the Gold Division, the Requirements Study is manaced by a senior User Manager (see Figure 4), who will have been selected because of the esteem in which he is held by the Divisional Executive and by his peer group on the mines. This is a commitment which the Division willingly gives, and it has already appointed this calibre of person to the four requirements studies that we have so far performed.

- For Materials Control - the General Manager of the Central Stores - this took three months.

- For Geology - the Chief Exploration Geologist - this took four months

- For Production Planning - a Section Manager from one of the rines - this took ten months.

- For Payroll - a company secretary from one of the mines this took three months.

Such a person would be too valuable to lead the project for its duration so we exchange project managers after the Requirements study - when the first question would have been answered - and appoint an experienced systems project manager for the remainder (see Figure 5). This project manager defines how the project will satisfy the given requirements, and, providing approval is obtained, proceeds to produce the system.

\subsection{PROJECT CONTROL PROCEDURES}

The project control procedures that we use are not rigid. Guidelines are given for what is the minimum that should appear in the documentation at the end of each phase, but we consider the Project Managers to be highly responsible people who should be allowed to use their initiative and not be tied by meaningless rules. In the Requirements study, the User Project Manager must, amongst other things, set out 


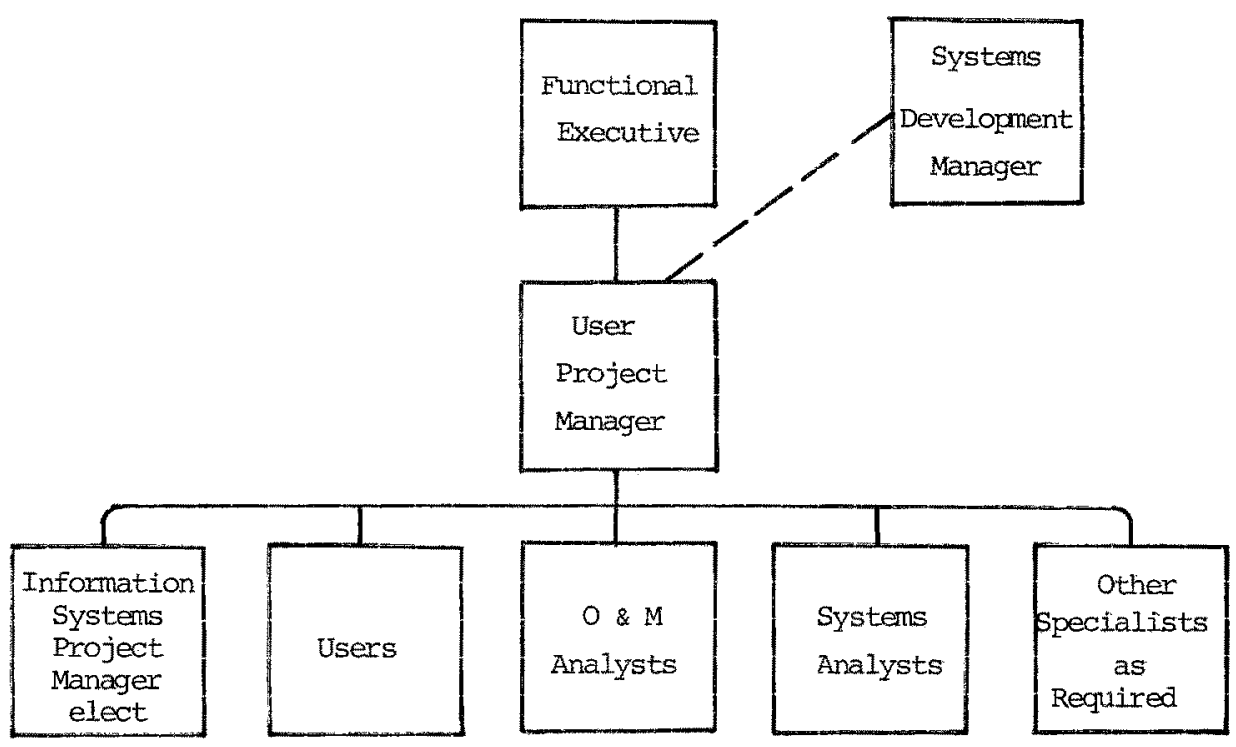

FIGURE 4: ORGANISATION STRUCTURE OF REQUTREMENIS STUDY PHASE

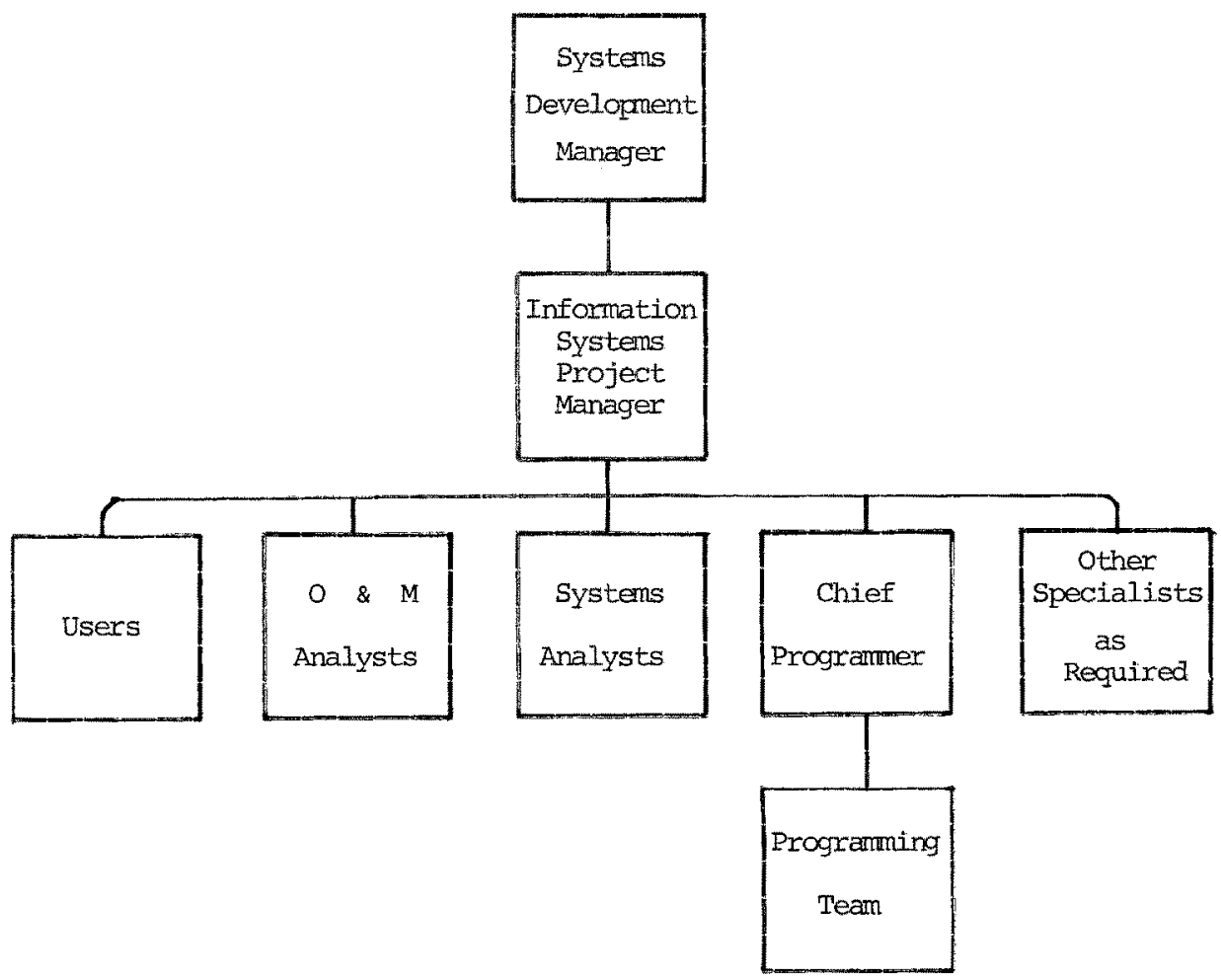


the sequence of deliverables, giving a budget and a delivery date for the first one. This commitment has to be supported by a detailed plan and it is against this plan that the systems Project Manager is controlled. There are no required monthly progress reports as this type of communication is given at informal progress sessions with the Systems Development Manager. The Development Manager does produce a consolidated report on all projects for Divisional Management, but this is really a public relations vehicle.

\subsection{PROJECT TEAM MEMBERSHIP}

In designing the membership of the project teams who will design and implement our systems, we took account of the recent experiences of three project teams employed by a South African Utility. Each team used a different approach. They were:

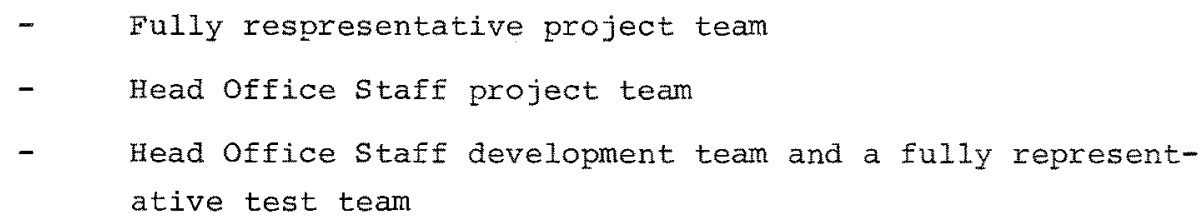

The first approach was used by the developers of a stock Recording and Costing system. This was a comon system. They assembled a project team under the leadership of the Head office Inventory Controller. The team consisted of the Inventory Controllers of each of the seven Divisions and an experienced Systems Analyst who knew Inventory Control theory, but who had no practical experience of storekeeping. This team of nine people realised that they were too many to do detailed design work, so they formed a working group comprising of the Project Leader and the Systems Analyst. The other team members received working papers containing the latest proposals in time for them to be read and checked against local circumstances before the regular monthly formal team meeting where they would be discussed and, if agreed, incorporated. This utility covered the whole of South Africa and it was decided that the monthly meeting would be held on a rotating basis in each of the major centres. This was more expensive than holding it in Johannesburg because, travel being more difficult, it necessitated the expense of all members save the host staying as a group overnight at a hotel. However the camaraderie built up during the course of this project became almost tangible. The system took four months to develop and, because it had to be implemented in eighty stores, it took six months to implement. 
Each divisional representative became the implementation co-ordinator for his division; the Systems Analyst supplied his team of four programmers to visit each store to explain the input forms and the reports, and he himself acted as central control; and the system went in with no major problems on time and on cost. There were many minor problems but, because of the team spirit, these were accepted and solved in a positive fashion.

The second approach was used by the Payroll project. This was also a Common system, and like the stores, had to be implemented throughout the Republic. This team, which was set up at the same time as the first and consequently could not draw on its experience, included only Head office members. The team, when it wanted something accepted by the Divisions, had the Personnel Manager issue a Head office order to to amend the appropriate procedure manual. The Project Leader, a senior member of the Personnel department, accompanied by his experienced systems Analyst, would also occasionally tour the Divisions to inform the paymasters of what was being developed for them. During these tours, because they could not carry all the details of the design with them, certain local queries were never satisfactorily answered. The first design was completed on time in four months but, during implementation at the project's pilot site, so many local anomalies were found that the team had to abandon its implementation and return to the design stage. This had side effects because the changes necessary were added on to the system like poor quality maintenance, rather then designed into it. Documentation suffered, and this aggravated the situation still further. In the end, the development phase took three years and the system was never really satisfactory to anybody.

The third approach was used by the Accounting project. This was a Central System, controlled by a senior accountant at Head office. When operational, it was proposed that the Divisions would submit their accounting transactions via their local computer (this Utility had a mini computer in every main centre of the Republic) for processing on the central hardware. There was to be a relatively complex month end closing procedure and, because the teleprocessing software was fairly primitive, any error found in an accounting batch caused the whole batch to be rejected. The project development team consisted solely of Head office personnel. In this case it was consciously decided that the people in the Divisions were not really of a calibre 
to be able to do development work. Progress reports on what the project team were considering were given at the quarterly Accountants meeting, but suggestions for improvement were not sought. Development took fifteen months and finished on 12 December. Implementation date was to be 1 January. December in South Africa is the start of the sumner holiday season. At the November Accountants meeting, the Divisions were invited to nominate a four-man acceptance test team, just to ensure that the system would work. In December, four Divisional accountants sat down to test the system. With the aid of the Accounting project's Systems Analyst, they learned how to do an acceptance test and then they set about putting a series of possible transactions through the system. The shortcomings of the design started to become apparent following the probing test data submitted by the test team. They dredged up from the depths of their experience all the tricky conditions that had ever happened to them, and in practically every case they scored a hit. All leave was cancelled and the development team and the test team sat down to rectify matters. Fortunately they had until the end of January to get things operational and, with much overtime and much praying, the deadline was met and the system implemented without any of the problems being visible to the company at large.

The membership of our project teams is a compromise between the first and the third approach just described. We have Users from the mines on the project teams and have other independent User involvement to ensure the project is as widely acceptable as possible - as will be described in the next section.

\subsection{USER INVOLVEMENT}

The last aspect of our organisation that I shall describe is user involvement. I have already mentioned that users are heavily involved as members of the project team throughout the life of the project. In addition there are three other major ways where we have User involvement.

The first of these is the Executive Committee. This is a committee representing senior Divisonal management. It is chaired by the Managing Director of the Orance Free State mines. Its membership includes director level personnel, and it has the responsibility, amongst other things, for initiating common (Divisional) projects and for approving the movement of each project from phase to phase. The project managers, when approval is required, give a short 
presentation on the project to date to the members. Really though, the Executive Committee procedures are only an exercise in communication because, being senior executives, it is impossible to expect the members to review in any detail the documentation produced. This is why another responsibility that the Comittee has is to appoint personnel in the Division who will do the detailed review of each project's work. This leads us to the second type of involvement - Divisional reviewing.

In practice, as many different people as possible are appointed to review different projects. This has the effect of increasing the visibility of our projects and directing the attention of various specialists to the task of reviewing. We have found this aspect of our methodology a very great success. Project managers really have to prove the worth of their systems to get approval to go to the next phase. This has the effect of motivating the systems people to produce a high quality product whose logic is faultless and which overwhelmingly proves to be a sound business decision. In our recent experiences, the various review bodies have:

- suspended the Payroll project as not having a sound enough business case to continue.

- refused to allow the Personnel Management system past its general design phase until a better system of security backup was devised.

- increased the scope of the Materials Control project to include an additional class of material.

- decreased the benefits claimed for one of the systems.

The third type of involvement is implementation. As stated previously our systems in Gold Division are designed for business processes, and not for organjsations. As the organisation on each mine could be different, a group of people are appointed with the task of implementing the system on their mine. This group is given training in the tasks expected of them and are constantly guided by the project team. They have to allocate the responsibilities for the system functions, build the facilities required, authorise the ordering of the equipment, carry out the training, do a test run of the system etc. These groups have been established on all our mines and the job is being tackled with great responsibility. 


\section{PROBLEMS}

Naturally, we have had problems in putting a few of these ideas into practice. Most of these occurred on the Personnel Management system. The reason why this system was particulary badly favoured was because it was the system identified by the BSP study as the first system to be developed. The methodology of BSP provided for the Requirements study of the first system to be done in parallel with the rest of the study, which in effect meant before the project control procedures had been put into place. This particular Requirements study was done to nowhere near an adequate level of detail. The scope and objectives of each of the deliverables were not defined and the time table was far too optimistic. The I.S. department had not yet been organised in a way to give adequate supervision to a project manager who, it soon became aprarent, was not sufficiently experlenced to cope with this very ambitious project. The project, to be fair, was enough to extend even the most experienced project manager. Everybody was having to learn new techniques - the South African Post Office was extended in implementing the data communcations network, data communications was new to Gold Division, new software and hardware was being installed and data bases were to be used extensively for the first time.

The project began to slip and the slide into chaos was getting faster because the Divisional reviewers would not allow the project past its General Design checkpoint. Information systems management was able only with difficulty to check the deterioration sufficiently to take corrective action. This needed great strength of character, because at no time did we pretend to our maragement that everything was going we11. They were informed of the truth and because of that we continued to have their support. We were able to appoint an outside consultant with proven experience in similar projects to leac the project. The previous project manager now reported to the new man. New functional specifications of the first deliverable were documented from scratch, and the Requirements Study phase was re-opened. The project is now heading in the right direction once again. It has slipped by a year but much of that was due to the cptimistic plan that was criginally set. On the other projects, we have had far fewer problems. This I believe is because they were only initiated after we had organised ourselves. One experience in Project Management that would be of interest is the following story as described to me by the I.S. Development Manager of a large South African 
company with several subsidiaries. This company was to implement a Management Accounting System. The accounting transactions were to come from existing resources control systems such as stores and payroll etc. Because the problem was so large, a project manager was appointed for the central accounting system and a different project manager was appointed for each of the interface systems which were to produce the transactions. Implementation date was to be lst JulY 1975 and the time allowed for development was six months which was more than adequate. Everybody made it - except the project manager of the Materials Control interface. Seeing that he was allowed six months, and having the interest of his User at heart (the Chief Buyer, unfortunately, not the Chief Accountant) he added a few "bells" and "whistles" that helped the Buying Department. He installed a part of a Purchasing package, but because this used CFMS files, he also had to introduce the IMS Bridge. Somehow or other this was not stopped by I.S. management. By the time April came, the project was in its $90 \%$ state and continued that way through May and June. I.S. management was in a dilemma. It could not abandon the whole exercise because the company was going to switch to its new accounting system on the 1st July. Ultimately, the Materials Control interface was delivered five months late. This meant that no materials costs could be reflected in the books of account during this time. Even by the end of the first year of running the new system, the initial five months backlog had only been reduced to three months. The direct effect of this misguidedness was that it took the company more than a year to be able to manage its affairs again, and it was only because it had a virtual monopooly of the market that it avoided having to cease trading. The project manager "left" and yet I feel that he was not the main person in error. An Information systems organisation must ensure that this type of occurrence is never able to take place.

\section{CONCLUSION}

In this paper I have attempted to deliver a practitioner's view of the organisation that must be in place before large Information Systems projects can be developed and implemented successfully. I have described the organisation that we have developed in the Gold Division of Anglo American and also a few situations experienced by ourselves and by other developers of large systems in South Africa. I have covered many points, and I will repeat the two main ones. 
Firstly systems are means by which a User manager organises his department in order to achieve his objectives. Making amendments to these systems is his prime responsibility as a manager. Therefore, even if he chooses a computer solution it is still his responsibility to design it, to test that it is correct and to make it work.

Secondly, the most important word in project development is control - especially quality control. This control should not be exercised in an oppressive fashion as would be the case if a supervisor were to be continually peeping over the shoulder of a Project Manager. Nevertheless the control, which we believe should be in the form of reviews, should be entrenched in the organisation so that, unless it satisfies the reviewers, a project should not be allowed to continue.

\section{ACKNOWLEDGEMENTS}

I would like to record my appreciation to the Management of the Gold Division of the Anglo American Corporation of South Africa for permission to publish and present this paper.

\section{BIBLIOGRAPHY}

1. Corporate Planning: A Practical Guide John Argenti - George Allen and Unwin Ltd, London.

2. The Executives New Computer oliver Wight - Reston Publishing Co. Inc. Reston, Virginia. 